\title{
O bjetivos moleculares para diseñar nuevos fármacos para el tratamiento de la diabetes tipo 2 y la obesidad
}

\author{
Raúl A. Bastarrachea1, Julio C. Montero², \\ Víctor Saavedra-G ajardo ${ }^{3}$, Ricardo Cerda-Flores ${ }^{4}$, \\ Anselmo Machado-D omínguez ${ }^{5}$, Anthony G. Comuzzie ${ }^{1}$. \\ Molecular targets for new drug discovery
to treat type 2 diabetes and obesity
}

Current strategies to treat type 2 diabetes (DMT2) include reducing insulin resistance using glitazones, supplementing with exogenous insulin, increasing endogenous insulin production with sulfonylureas and meglitinides, reducing hepatic glucose production through biguanides, and limiting postprandial glucose absorption with alphaglucosidase inhibitors. In all of these areas, new generations of molecules with improved efficacy and safety profiles, are being investigated. Promising biological targets are rapidly emerging such as the role of lipotoxicity as a cause of glucometabolic insulin resistance, leading to a host of new molecular drug targets such as AMP-activated protein kinase (AMPK) activators, recombinant adiponectin derivatives, and fatty acid synthase (FAS) inhibitors. Insulin action can be enhanced in muscle, liver and fat, with small-molecule activators of the insulin receptor or inhibitors of protein tyrosine phosphatase (PTP)-1B. Defective glucosestimulated insulin secretion by pancreatic $\beta$-cells could be alleviated with recombinant glucagon-like peptide (GLP-1) or agonists to the GLP-1 receptor. This review presents a new approach for obesity and DMT2 drug discovery through pharmacogenomics. Several compounds have already been validated through genetic engineering in animal models or the preliminary use of therapeutic compounds in humans (Rev Méd Chile 2008; 136: 107-17).

(Key w ords: Diabetes, type 2; Obesity; Pharmacogenetics)

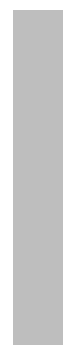

\begin{abstract}
Recibido el 12 de octubre, 2006. Aceptado el 11 de enero, 2007.
${ }^{1}$ Department of Genetics, Auxology and Metabolism Working Group, Southwest Foundation for Biomedical Research, San Antonio, Texas, USA. ${ }^{2}$ Centro de Docencia e Investigación, Sociedad Argentina de Obesidad y Trastornos Alimentarios. Departamento Docente de la Asociación Médica Argentina, extensión de la Universidad Nacional de Buenos Aires, Buenos Aires, Argentina. ${ }^{3}$ Facultad de Medicina y Facultad de Odontologia, Universidad Mayor. Santiago de Chile. ${ }^{4}$ Departamento de Genética de Población y Bioinformática, Centro de Investigación Biomédica del Noreste, Instituto Mexicano del Seguro Social. Monterrey, Nuevo León, México. ${ }^{5}$ Clínica de Nutrición y Obesidad, Hospital General, Secretaría de Salud Pública, Ciudad Obregón, Sonora, México.
\end{abstract}

Correspondencia a: Dr. Raúl A. Bastarrachea. Auxology and Metabolism Working Group, Department of Genetics. Southwest Foundation for Biomedical Research. P.O. Box 760549, San Antonio, Texas 78245-0549. (210) 258-9731 / Fax (210) 670-3317. E mail: raulbs@darwin.sfbr.org 
T a fisiopatologia de la diabetes mellitus tipo 12 (DMT2) se caracteriza por dos alteraciones: a) resistencia a la insulina, definida como la incapacidad de esta hormona para suprimir la producción hepática de glucosa y estimular la captación periférica de glucosa por el músculo y b) el compromiso de la función de la célula $\beta$ pancreática, en la que la secreción insulínica es insuficiente para compensar dicha resistencia. El resultado es la hiperglicemia característica del paciente diabético. El diabético cursa con niveles elevados de ácidos grasos libres (AGL) y de triglicéridos. Estos AGL parecen ser fundamentales para la resistencia a la insulina, por estimular la producción de glucosa hepática y por inhibir el transporte de glucosa al interior del músculo ${ }^{1}$. La identificación de procesos moduladores de la expresión genética de proteínas y de enzimas claves de los caminos metabólicos y bioquímicos que juegan un papel primordial en la patogénesis de la obesidad y la DMT2, ha dejado al descubierto una amplia variedad de objetivos moleculares. Existe optimismo en que, a mediano plazo, se pueda contar con fármacos cuyo mecanismo de acción se desarrolle a través de objetivos endocrinomoleculares específicos. Este artículo revisa los novedosos enfoques moleculares que han identificado futuros objetivos farmacogenómicos en el campo de las enfermedades metabólicas.

Identificando objetivos endocrinomoleculares para desarrollar nuevos fármacos para la obesidad y la DMT2. El avance del conocimiento genómico ha podido identificar nuevos objetivos moleculares farmacológicos que se han agrupado en categorías según su mecanismo de acción ${ }^{2}$ (Figura 1):

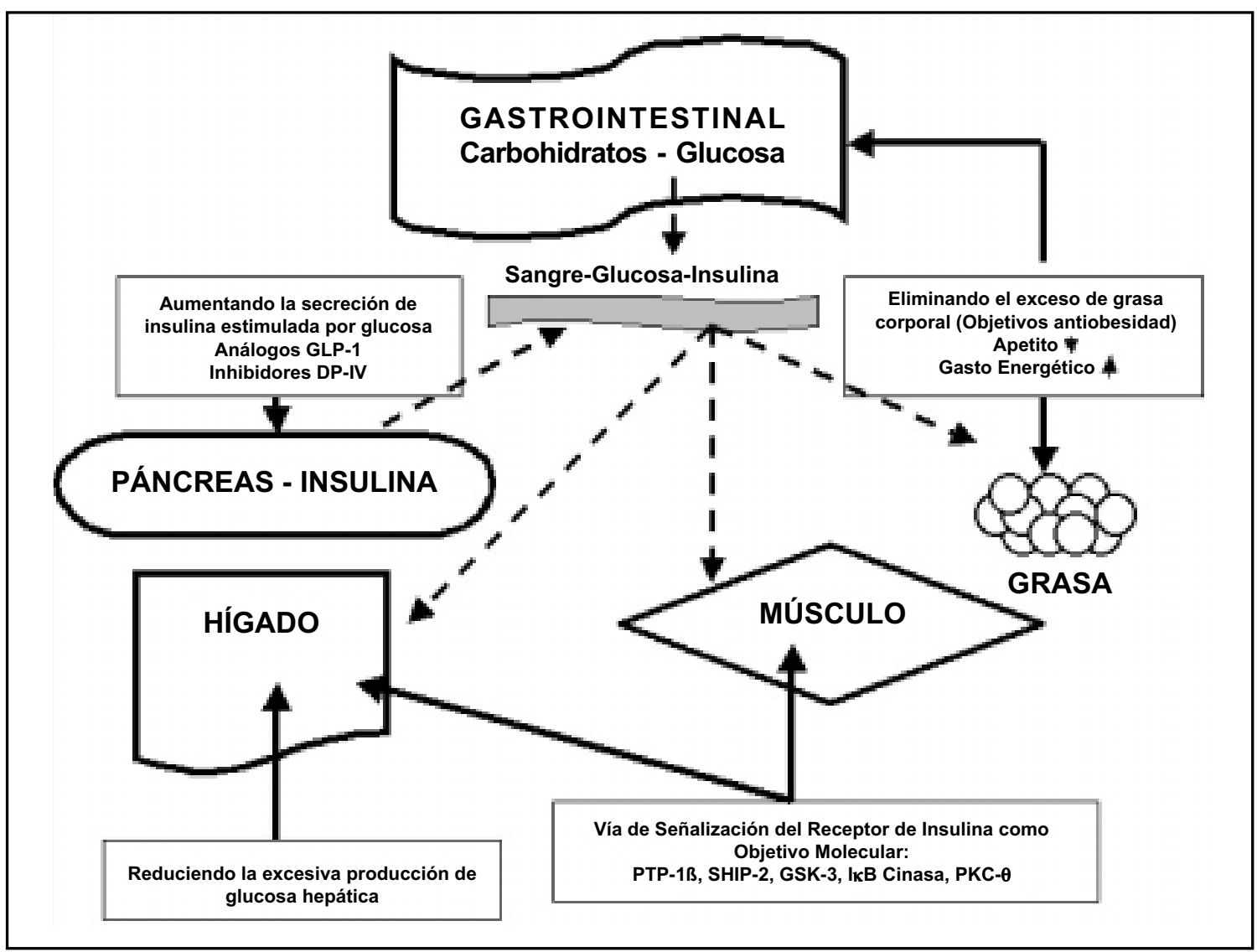

Figura 1. Enfoque farmacogenómico a través de categorías mecanísticas dirigidas a objetivos moleculares específicos para tratar la obesidad y la diabetes tipo 2. (Las flechas punteadas indican el flujo de glucosa e insulina desde el sistema gastrointestinal y el páncreas a través del torrente sanguíneo hacia el tejido adiposo, músculo e hígado). 
A. Fármacos para disminuir la adiposidad y corregir la lipotoxicidad ${ }^{3}$

1. Agonistas del receptor de melanocortina MC4R.

2. Agonistas selectivos del receptor de serotonina 5-HT2C.

3. Agonistas de la colecistoquinina A (CCK-A).

4. Fármacos antiobesidad visceral (ligandos PPARg).

5. Liporregulación farmacológica (antiesteatosis).

6. Análogos de la adiponectina

B. Fármacos reductores de la producción excesiva de glucosa hepática

1. Antagonistas del receptor de glucagón.

2. Inhibidores de la fosforilasa hepática de glucógeno.

3. Inhibidores de la glucosa 6 fosfatasa.

4. Antagonistas selectivos del receptor hepático de glucocorticoides.

C. Fármacos que incrementan la secreción de insulina estimulada por glucosa (incretinas)

1. Agonistas del péptido semejante a glucagón (GLP-1) (Exendin 4).

2. Inhibidores de la dipeptidilpeptidasa-IV (DP-IV).

3. Inhibidores de la piruvato deshidrogenasa quinasa (PDHK).

4. Activadores de la glucokinasa (GK).

D. Fármacos específicos para objetivos moleculares en la vía de señalización de la insulina

1. Inhibidores de la proteína tirosina-fosfatasa 1B (PTP-1B).

2. Inhibidores de la glucógeno sintetasa quinasa-3 (GSK-3).

3. Activadores no peptídicos del receptor de insulina.

4. Antagonistas de la proteína quinasa C (PKC).

Por necesidad de espacio se revisarán solamente las opciones que a consideración de los expertos son los enfoques farmacológicos más relevantes en un futuro cercano.

Liporregulación farmacológica (antiesteatosis). La leptina es considerada actualmente como la principal hormona liporreguladora, al mantener una homeostasis lipídica intracelular normal, de la misma forma que la insulina es requerida para una normal glucorregulación. La leptina, al unirse a su receptor OB-R en la membrana celular, induce la fosforilación de una proteína denominada STAT-3 que, al activarla, penetra al núcleo, regulando y controlando la actividad transcripcional de genes denominados lipogénicos y lipooxidativos. La leptina disminuye la actividad de factores de trascripción lipogénicos, principalmente PPAR $\gamma 2$ y, en el hepatocito, la proteína transportadora del elemento regulador de esteroles SREBP-1c. A través de estas acciones, induce una disminución en la expresión de las enzimas lipogénicas acetil CoA carboxilasa (ACC) y la sintetasa de ácidos grasos (FAS), incrementando la expresión de enzimas clave en la oxidación de los ácidos grasos como la acil CoA oxidasa (ACO) y la carnitinpalmitoil transferasa (CPT-1). Al mismo tiempo, la leptina incrementa la actividad de la AMP-quinasa (AMPK), cuya acción es bloquear la formación de ACC. Este es el paso clave de su efecto lipooxidativo, limitando de esta manera la acumulación de grasa intracelular en tejidos no adiposos (músculo, hígado y célula beta), efecto también denominado antiesteatósico (Figura 2). La ACC es el eslabón principal para la síntesis de triglicéridos y de ácidos grasos. Si la expresión de malonil CoA es inhibida, se desinhibe a su vez la expresión de la enzima CPT1 , provocando de esta manera una adecuada oxidación mitocondrial de ácidos grasos. La leptina incrementa también la expresión intracelular del coactivador- $1 \alpha$ de PPAR $\gamma$ (PGC-1 $\alpha$ ), incrementando de esta manera la actividad enzimática mitocondrial para la oxidación de ácidos grasos y la biogénesis mitocondrial (Figura 2). Cuando existe resistencia a la leptina, la AMPK no ejerce su inhibición sobre ACC, con lo que se sobreexpresa la enzima malonilcoenzima A (CoA) y se incrementa la síntesis de triglicéridos y ácidos grasos, bloqueándose simultáneamente su oxidación al inhibir a la CPT-1. (Figura $3)^{4}$. De una manera didáctica, la leptina bloquea los genes que acumulan grasa (lipogénicos o ACC y FAS), y estimula la expresión de los genes que oxidan grasa (lipooxidativos o ACO y CPT-1).

Dos compuestos clasificados como inhibidores de la sintetasa de ácidos grasos (FAS), denominados cerulenin y el compuesto sintético C75, causaron una significativa pérdida de peso e inhibición del apetito al administrarlos a roedores, tanto por vía sistémica como por vía intracerebroventricular. Se pudo observar que C75 en especial, inhibió la señal profágica (estímulo de comer) producido por el neuropéptido Y (NPY) en el hipotálamo, actuando de manera independiente a las acciones de la leptina ${ }^{5}$. Un aspecto sobresaliente de estos recientes conceptos en genética y biología molecular de 


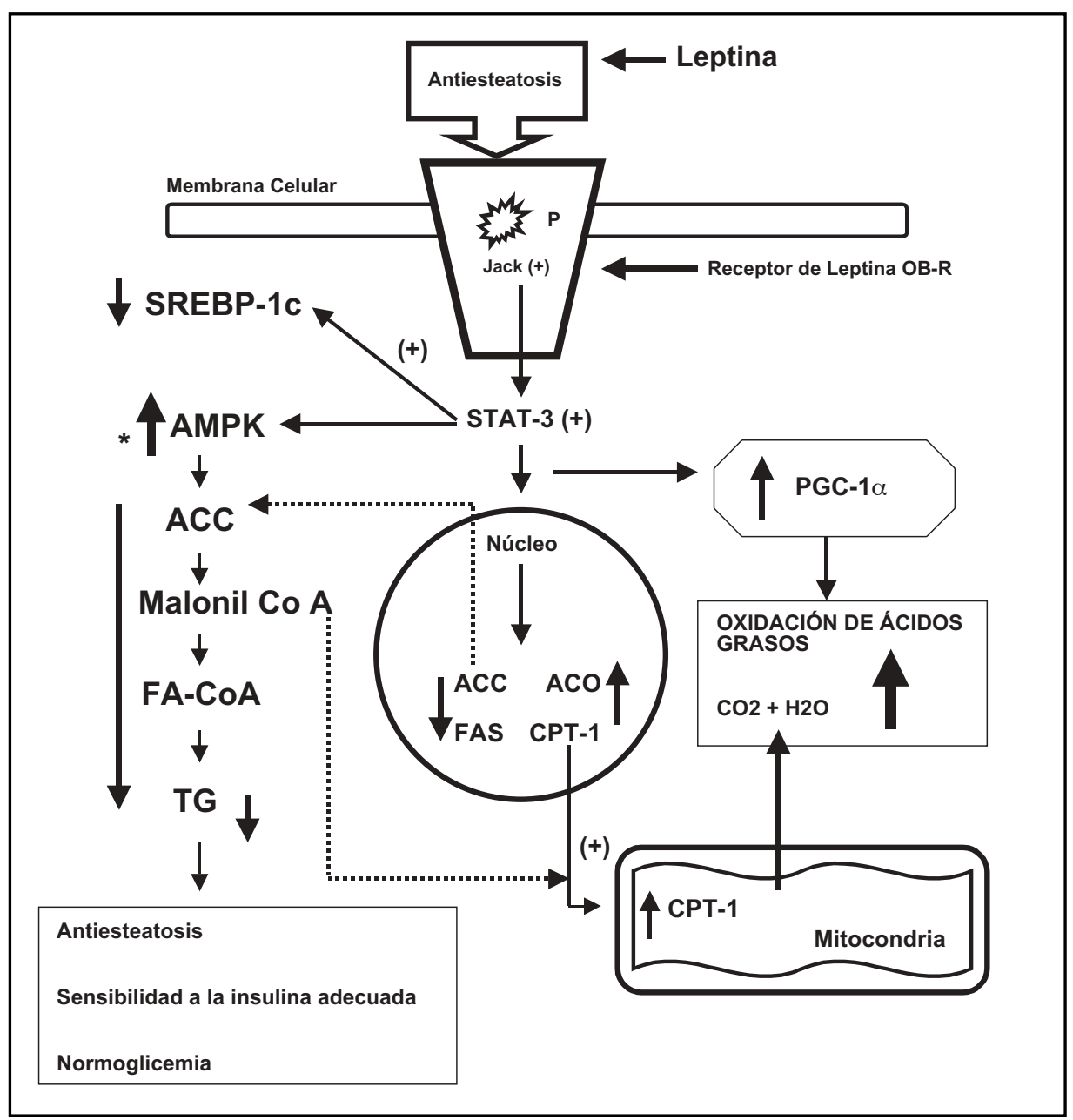

Figura 2. Fisiología molecular de la liporregulación. Antiesteatosis secundaria a una adecuada señalización de la leptina. "Paso metabólico clave.

la liporregulación, ha derivado en esclarecer el objetivo molecular preciso de la ampliamente utilizada metformina. Todo parece indicar que el mecanismo de acción por el que la metformina inhibe la producción hepática de glucosa, y atenúa la esteatosis hepática, es precisamente activando la AMPK (Figura 3) ${ }^{6}$. Estas observaciones han fortalecido la hipótesis unificada de la lipotoxicidad, que implica que la DMT2 es causada por una acumulación de triglicéridos y ácidos grasos de cadena larga en el interior de tejidos no adiposos claves (páncreas, músculo, hígado). Esta esteatosis parece ser revertida o prevenida por una apropiada señalización de la leptina a nivel de su receptor ${ }^{7}$.
Análogos de la adiponectina. La adiponectina se expresa exclusiva y específicamente en el adipocito. Se encuentra inversamente relacionada a la cantidad de grasa visceral, es decir, a mayor acumulación de grasa visceral, menor adiponectina circulante ${ }^{8,9}$. Se ha demostrado que los niveles de adiponectina se encuentran disminuidos en pacientes diabéticos cuando se comparan con los de sujetos sanos sin diabetes, sugiriendo que la hipoadiponectinemia es un factor de riesgo importante en el desarrollo de resistencia a la insulina y de diabetes tipo $2^{10,11}$. Coincidiendo con el mayor riesgo causado por esta enfermedad, los niveles de adiponectina se encuentran significativamente disminuidos en la enferme- 


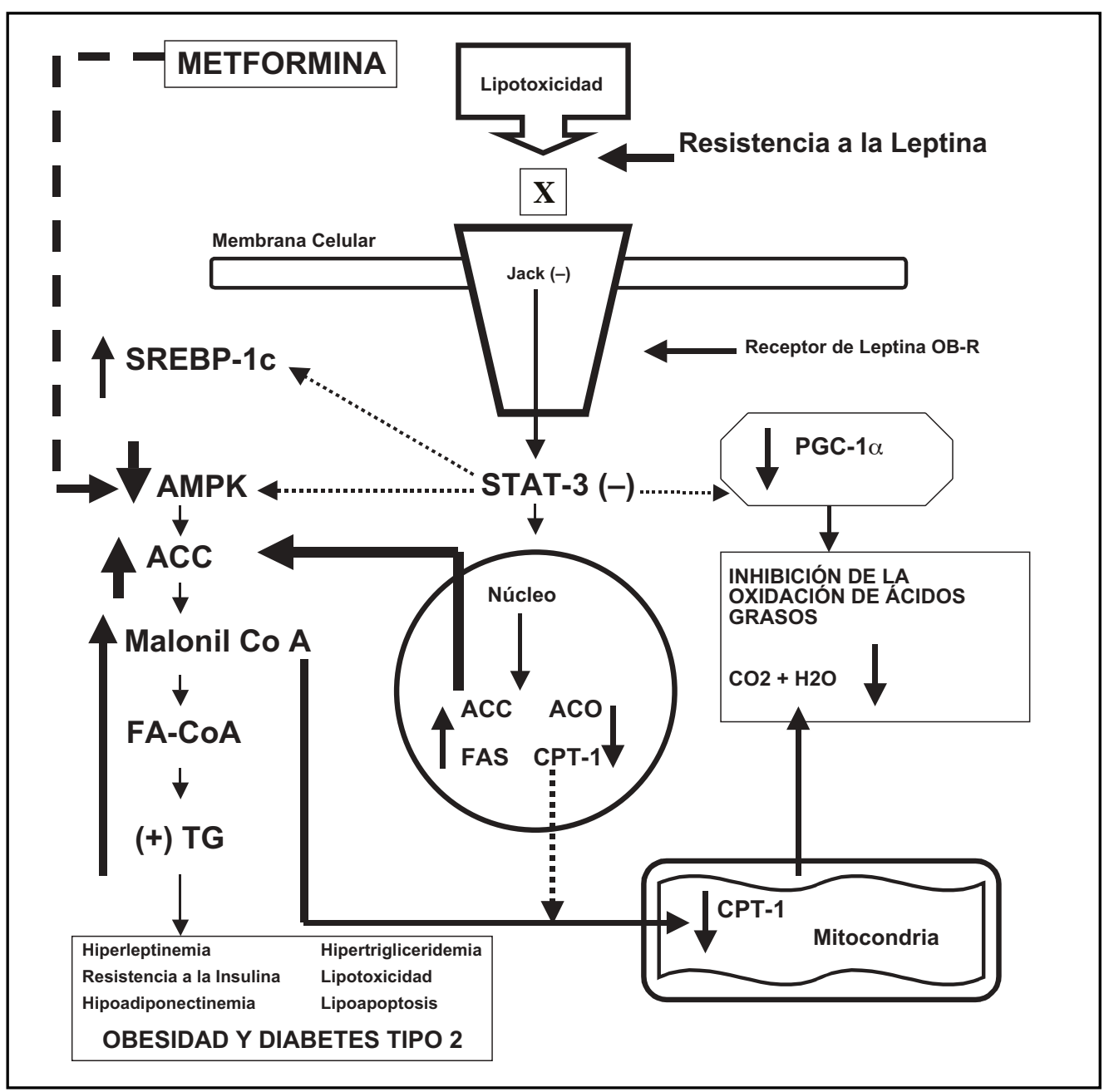

Figura 3. Fisiopatología molecular de la liporregulación. Resistencia a la leptina como factor central en el desarrollo de obesidad y diabetes tipo 2 a través de precursores que dan lugar a generadores primarios como hiperleptinemia, hipertrigliceridemia, resistencia a la insulina, lipotoxicidad, hipoadiponectinemia y lipoapoptosis.

dad isquémica coronaria. El riesgo en un individuo de cursar con un proceso isquémico aterotrombótico coronario, aumenta considerablemente cuando sus niveles de adiponectina son menores a $4 \mu \mathrm{g} / \mathrm{mL}^{12}$.

Tanto la adiponectina como el factor de necrosis tumoral-alfa (TNF- $\alpha$ ) actúan de manera antagónica sobre macrófagos y adipocitos. A mayor cantidad de TNF- $\alpha$ en los adipocitos y macrófagos, menor es la expresión de adiponectina. En otras palabras, el TNF$\alpha$ y la adiponectina son antagonistas moleculares citosólicos $^{13}$. La adiponectina es transportada desde el tejido adiposo por el torrente sanguíneo y penetra al endotelio vascular previniendo los tres pasos más importantes de la formación de la placa ateromatosa: a) bloquea la migración y activación de las células de músculo liso vascular, b) bloquea la expresión de las moléculas de adhesión intracelulares (ICAM por sus siglas en inglés) y vasculares (VCAM por sus siglas en inglés), impidiendo la penetración de monocitos al endotelio y la formación de macrófagos y c) bloquea, en los macrófagos mismos, la expresión de sus receptores carroñeros y de esta manera inhibe la captura de lipoproteínas de baja densidad (LDL) oxidadas y la formación de la célula espumosa ${ }^{14}$.

Actualmente se está trabajando intensamente para desarrollar derivados recombinantes de adi- 
ponectina o moléculas agonistas no peptídicas. Hasta el momento, se ha podido aislar exitosamente el fragmento biológicamente activo de la adiponectina humana, denominada famoxina ${ }^{15}$.

Vías de señalización molecular insulínica. El receptor de insulina es una quinasa de tirosina que sufre autofosforilación, catalizando a su vez la fosforilación de proteínas celulares tales como los miembros de la familia de los substratos del receptor de insulina, denominados IRS. Inmediatamente después de su fosforilación, estas proteínas interactúan con moléculas de señalización intracitosólicas, dando lugar a una amplia serie de vías de señalización molecular en el citosol, que transmiten el mensaje de la insulina hacia factores de transcripción en la membrana nuclear. Esta activación molecular incluye dos vías principales: la vía de la proteína cinasa activadora de la mitogénesis (MAP), denominada la vía mitogénica y la fosfatidilinositol3-OH quinasa estimulada por insulina (PI-3K), denominada la vía metabólica. Estas vías moleculares actúan de forma integrada para coordinar la regulación del tráfico vesicular, la síntesis de proteinas, la activación y la inactivación de enzimas clave y, principalmente, la expresión genética desde el núcleo de transportadores de glucosa (denominados GLUT), cuyo resultado final es la regulación del metabolismo de la glucosa, de los lípidos y de las proteinas ${ }^{16}$ (Figura 4 ).

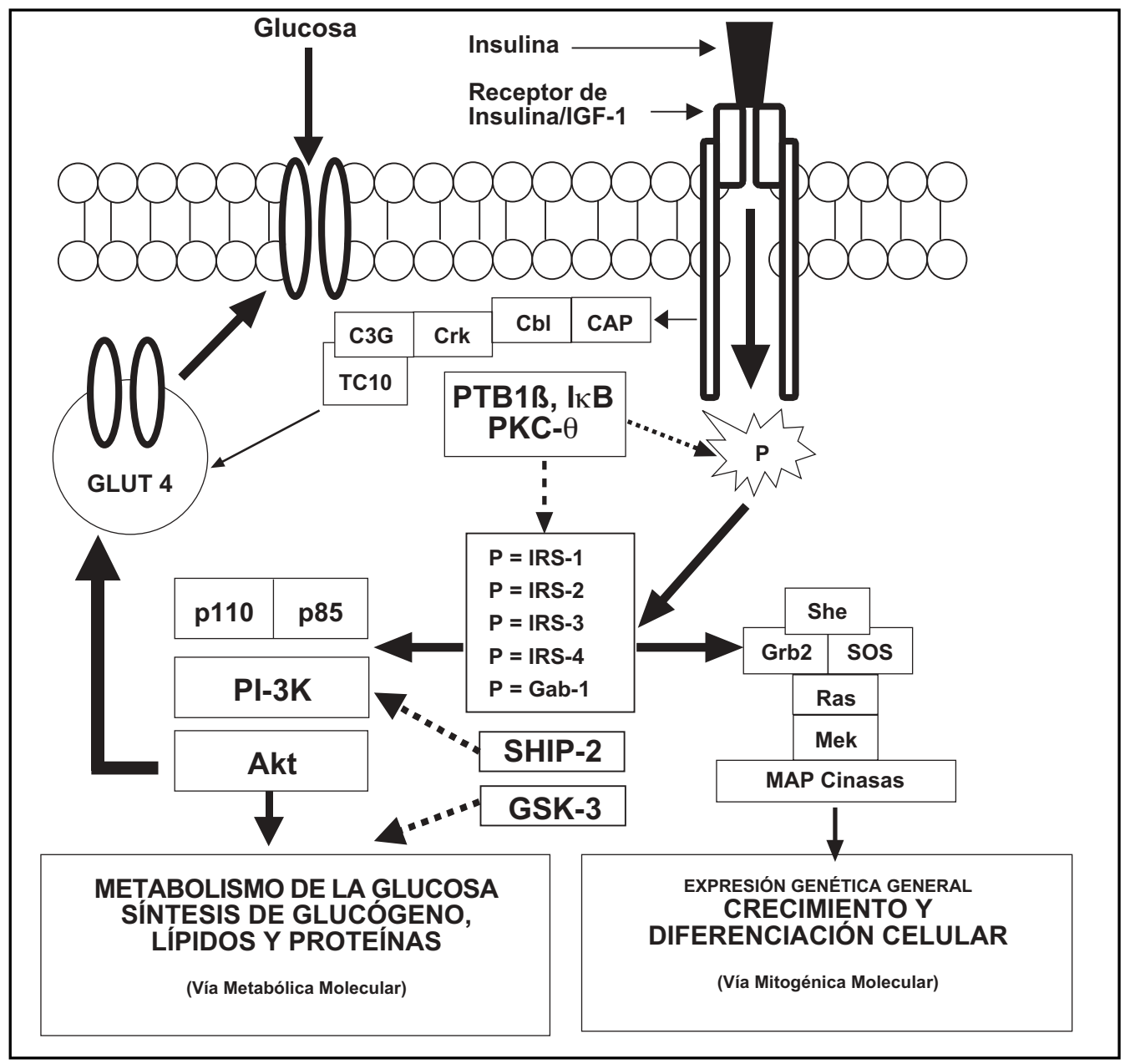

Figura 4. Vías moleculares de señalización de la insulina. Flechas punteadas: inhibición de la señalización (resistencia a las acciones de la insulina). Flechas continuas: señalización apropiada (sensibilidad a las acciones de la insulina). 
La PI-3K tiene un papel esencial en las acciones metabólicas y mitogénicas de la insulina ${ }^{17}$. Los inhibidores de la PI-3K bloquean la mayoría de las acciones metabólicas de la insulina ${ }^{18,19}$. La PI-3K regula y activa la $\mathrm{Akt}^{20,21}$. Se ha sugerido que Akt es clave importante en la transmisión de la señal intracitosólica de la insulina al fosforilar la enzima GSK-3. Esta enzima tiene efectos opuestos a la insulina, inhibiendo la acción de la glucógeno sintetasa en el músculo. Los inhibidores selectivos de la GSK-3 incrementan las acciones de la insulina in vivo 22,23 (Figura 4).

La PTP-1B es una enzima intracelular específicamente implicada en la regulación negativa de la señalización de la insulina. Los roedores mutantes a los que se le ha eliminado el gen que expresa la proteína PTP-1B, son saludables y presentan una marcada sensibilidad a las acciones de la insuli$\mathrm{na}^{24}$. Una validación adicional de PTP-1B como un objetivo farmacogenómico, ha sido proporcionada por la evidencia de una acción incrementada de la insulina en ratas resistentes a la insulina tratadas con un oligonucleótido antisentido para PTP-1B. Este tratamiento parece haber funcionado con inyecciones del oligonucleótido una o dos veces a la semana y podría ser un enfoque viable para ensayar en humanos ${ }^{25}$.

El papel del complejo IKK/NF-Kß en disminuir las acciones moleculares de la insulina es conocido ampliamente 26,27 . El factor de trascripción nuclear NF-Kß desempeña un papel primordial en la regulación de la expresión de citocinas (citoquinas) y proteínas inmunorreguladoras. Su actividad es desencadenada por el factor de necrosis tumoralalfa (TNF- $\alpha)$. Altas dosis de salicilato pueden producir una mayor sensibilidad a las acciones de la insulina y se asocian a una inhibición de la expresión de IKK. Como el TNF- $\alpha$ (ampliamente identificado como mediador de resistencia a la insulina asociada a la obesidad ${ }^{28}$ puede activar el complejo IKK/NF-Kß, la implicación del papel específico que desempeña IKK en la resistencia a la insulina mediada por TNF- $\alpha$ parece ser inobjetable.

Las proteínas-quinasa C (PKCs) son isoenzimas activadas por la hiperglicemia y otros estímulos. Una de sus isoformas, la PKC- $\beta$ es preferencialmente activada por niveles elevados de glucosa y se ha asociado fuertemente a complicaciones vasculares diabéticas. El mesilato de ruboxistaurina es un nuevo inhibidor selectivo de las PKC- $\beta$, y ha demostrado en modelos animales in vivo e in vitro un buen potencial para reducir las complicaciones vasculares asociadas con la DMT2. Los estudios en fases II y III han confirmado la eficacia de este compuesto en ejercer una influencia favorable en la evolución de las complicaciones microvasculares diabéticas ${ }^{29}$.

Incretinas (hormonas peptídicas gastrointestinales). Un componente clave en la fisiopatología de la diabetes tipo 2, es el defecto selectivo en la capacidad de la glucosa para provocar secreción de insulina por la célula $ß$ pancreática ${ }^{30}$. Este mecanismo ha llevado a buscar enfoques alternativos para potenciar la secreción de insulina de una manera directa y dependiente de la glucosa exclusivamente, diferentes al modo de acción de las sulfonilureas, que estimulan la secreción de insulina en ausencia de niveles elevados de glucosa, al bloquear los canales de $\mathrm{K}+$ sensibles a ATP.

De este concepto ha surgido la atención sobre dos hormonas denominadas péptido semejante al glucagón-1 o GLP-1 y el péptido inhibitorio gástrico o GIP, conocidas como incretinas u hormonas gastrointestinales, que al actuar sobre sus respectivos receptores acoplados de proteína $G$ en las células $\beta$, potencian la secreción de insulina estimulada por glucosa ${ }^{31}$ (Figura 1). La administración de cualquiera de las dos hormonas a humanos, puede potenciar la secreción de insulina. También, el bloqueo (knock out) selectivo de los genes que expresan los receptores para GLP-1 o GIP, dan lugar a un fenotipo de alteración en los niveles de glucosa y secreción de insulina ${ }^{32}$. Mecanismos adicionales por los que GLP1 pudiera tener efectos antidiabéticos incluyen una inhibición del vaciamiento gástrico, una alteración en la secreción de glucagon y efectos potenciales anorexigénicos centrales, pero quizá el dato más relevante es la posibilidad de que el GLP-1 tenga potencial para promover el crecimiento de nuevos islotes y cause hiperplasia de las células $\AA^{31}$.

Aunque GLP-1 y GIP tienen un potencial enorme como opción terapéutica para tratar la diabetes tipo 2, ambos compuestos están expuestos a sufrir una degradación muy rápida por dipeptidilpeptidasa-IV (DP-IV). GLP-1 es un producto del gen de pre-pro-glucagón. Pro-glucagón es separado por clivaje por la prohormona convertasa-1, que da lugar a la aparición de GLP1, generando su secreción desde las células 
intestinales L durante la ingestión de nutrientes ${ }^{32}$. GLP-1 es rápidamente hidrolizado in vivo en menos de un minuto, dando lugar a un producto inactivo. DP-IV es la única responsable de esta inactivación. Por lo tanto, los inhibidores de DPIV representan un enfoque terapéutico indirecto para estabilizar GLP-1 endógeno, pudiendo ser utilizados como herramientas antidiabéticas. La validación de DP-IV como objetivo molecular terapéutico relevante se obtuvo de observaciones en roedores que al eliminárseles DP-IV, tenían niveles incrementados de GLP-1, un aumento en la secreción de insulina y un fenotipo saludable ${ }^{33}$. Ensayos clínicos en fases tempranas en humanos han demostrado la eficacia de la inhibición de DP-IV en diabéticos tipo 2. Otro enfoque a este problema podría ser la utilización de péptidos análogos de GLP-1 resistentes a DPIV $^{34}$. En abril de 2005, la Food and Drug Administration (FDA) de los Estados Unidos de Norteamérica aprobó el uso de exenatide, un fármaco derivado de la saliva del monstruo de Gila, como terapia adjunta para pacientes cuyos niveles de glucosa no se encuentran apropiadamente controlados con metformina o sulfonilureas. Exenatide es un análogo sintético de GLP-1 derivado del exedin-4, que es la proteína que reside en la saliva del monstruo 35,36 . En resumen, los efectos terapéuticos para incrementar las acciones de las incretinas han sido altamente alentadores. El exenatide y el liraglutide son muestras claras del avance farmacogenómico antidiabetes. La administración oral de inhibidores DPP-IV, como la sitagliptina y la vildagliptina, son otros ejemplos claros de esta vía molecular para desarrollar agentes antidiabéticos, que al parecer también ofrecen efectos benéficos sobre la célula $ß$. El desarrollo de análogos de GLP-1 e inhibidores de DP-IV es una muestra del avance de la farmacogenómica en pacientes con diabetes tipo $2^{37}$.

Glucocorticoides y la regulación de glucosa hepática. Los glucocorticoides (GCs) juegan un papel importante en la regulación de la liberación de glucosa hepática. Una elevación de glucocorticoides resulta en resistencia a la insulina e hiperglicemia, y una reducción de GCs mejora la sensibilidad a las acciones de la insulina ${ }^{38}$. El diseño de antagonistas del receptor de glucocorticoides (GC-Rs) bloquea sus efectos fisiológicos. Sin embargo, el crítico papel que juegan los GCs en el eje hipotálamo-pituitario-adrenal y los inconvenientes potenciales (hipertensión, fatiga crónica, hipersecreción de cortisol) que podrían ocurrir debido a un bloqueo no selectivo del GC-R, obliga a requerir un antagonismo altamente selectivo en el hígado del receptor de glucocorticoides para tratar de manera segura la diabetes tipo 2. Se ha presentado el primer antagonista hepático selectivo del GC-R denominado A-348441. La eficacia de este compuesto para disminuir la glucosa sanguínea fue observada consistentemente en roedores mutantes diabéticos ob/ob, en ratas Zucker fa/fa y en perros no anestesiados. A-348441 redujo de 25 a $61 \%$ la liberación hepática de glucosa en las ratas Zucker fa/ fa insulinoresistentes, con dosis orales de hasta 100 $\mathrm{mg} / \mathrm{kg} /$ día por un periodo de 8 días. A-348441 representa un novedoso enfoque para el tratamiento de la diabetes tipo 2, al inhibir selectivamente los receptores hepáticos de glucocorticoides ${ }^{39}$.

Más allá del control de las acciones del glucagón, varias enzimas que regulan los pasos bioquímicos en las vías gluconeogénicas o glucogenolíticas son objetivos moleculares obvios para intervención terapéutica (Figura 5). Un enfoque, aún en etapas preliminares de investigación, consiste en la inhibición del producto proteico codificado por el gen que expresa la fosforilasa de glucógeno hepática. Esta enzima cataliza la liberación de glucosa monomérica a partir del glucógeno almacenado. Los inhibidores de la fosforilasa de glucógeno inhiben la liberación de glucosa al disminuir el catabolismo del glucógeno hepático ${ }^{40}$.

\section{Conclusiones}

El avance científico en el campo molecular empieza a desplazar a los enfoques basados en objetivos enzimáticos o receptores "clásicos", para adentrarse en terapias genómicas. Dada la naturaleza multifactorial de los factores genéticos y ambientales que contribuyen a la aparición de la obesidad y la diabetes tipo 2, es muy probable que los esfuerzos futuros se dirijan a "subfenotipos" de enfermedad y de marcadores genéticos que serán traducidos en terapias más selectivas, ensambladas individualizadamente para estos distintos subgrupos de pacientes o sujetos en riesgo de desarrollar el padecimiento. 


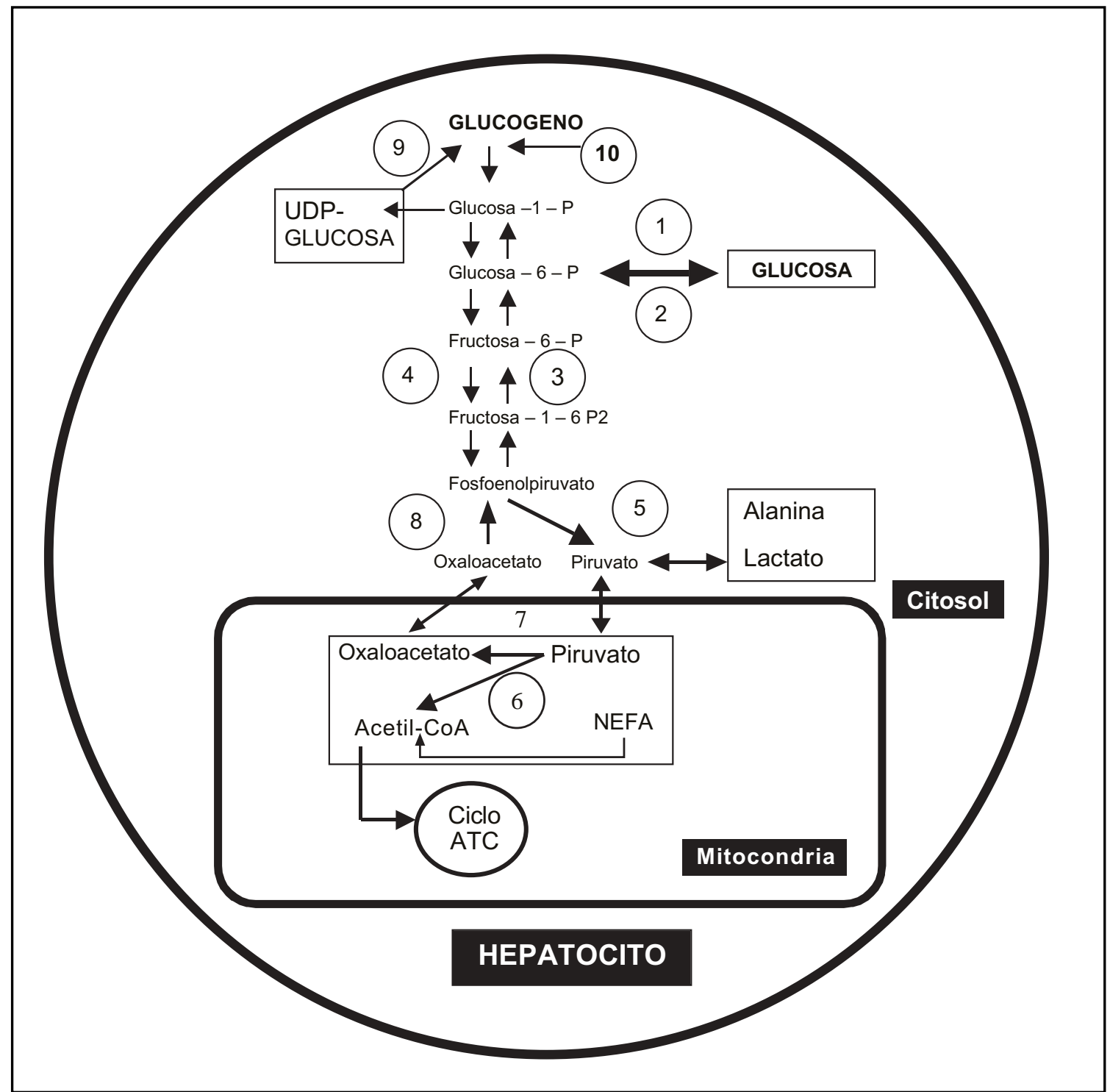

Figura 5. Objetivos enzimáticos hepáticos expresados por genes que regulan las vías bioquímicas gluconeogénicas y glucogenolíticas. 1. Glucosa-6-fosfatasa. 2. Glucoquinasa. 3. Fosfofructoquinasa-1. 4. Fructosa-1-6-bifosfatasa. 5. Piruvato quinasa. 6. Piruvato deshidrogenasa. 7. Piruvato carboxilasa. 8. PEPCK. 9. Glucógeno sintetasa. 10. Glucógeno fosforilasa. (NEFA: ácidos grasos no esenciales).

Seguramente, estos individuos serán identificados en base a genotipos de subgrupos étnicos, o marcadores clínicos específicos para alteraciones fisiológicas o bioquímicas distintas. No cabe duda que el conocimiento colectivo basa- do en la biología molecular y la genómica funcional sobre las vías celulares que explican los rasgos fisiopatológicos de la obesidad y la diabetes tipo 2 se encuentran en rápida expansión. 


\section{REFERENCIAS}

1. Shafrir E, Raz I. Diabetes: mellitus or lipidus? Diabetologia 2003; 46: 433-40.

2. Wagman As, Nuss JM. Current therapies and emerging targets for the treatment of diabetes. Curr Pharm Des 2001; 7: 417-50.

3. Bastarrachea Ra, Tejero E, Cai G, Comuzzie AG. Farmacogenómica de la diabesidad: Corrigiendo las alteraciones glucolipometabólicas secundarias a un exceso de tejido adiposo Rev Edocrinol Nutr 2004; 12: 80-9.

4. UNGER RH. Minireview: weapons of lean body mass destruction: the role of ectopic lipids in the metabolic syndrome. Endocrinology 2003; 144: 5159-65.

5. Loftus TM, Jaworsky DE, Frehywot GL, Townsend CA, Ronnett GV, Lane MD et al. Reduced food intake and body weight in mice treated with fatty acid synthase inhibitors. Science 2000; 288: 229-300.

6. Zhou G, Myers R, Li Y, Chen Y, Shen X, FenykMelody J ET AL. Role of AMP-activated protein kinase in mechanism of metformin action. J Clin Invest 2001; 108: 1167-74.

7. Lee Y, Wang MY, KaKuma T, Wang ZW, Babcock E, MCCORKLE K ET AL. Liporegulation in diet-induced obesity. The antisteatotic role of hyperleptinemia. J Biol Chem 2001; 276: 5629-35.

8. Comuzzie A, Funahashi T, Sonnenberg G, Martin L, JACOB H, AnNe E ET AL. The Genetic Basis of Plasma Variation in Adiponectin, a Global Endophenotype for Obesity and the Metabolic Syndrome. J Clin Endocr and Metab 86: 4321-5.

9. Matsusawa Y, Funahashi T, Kihara S, Shimomura I. Adiponectin and Metabolic Syndrome. Arterioscler Thromb Vasc Biol 2003; 23: 29-33.

10. Lindsay RS, Funahashi T, Krakoff J, Matsuzawa Y, Tanaka S, Kobes S et al. Genome-Wide Linkage Analysis of Serum Adiponectin in the Pima Indian Population. Diabetes 2003; 52: 2419-25.

11. Savage PJ, Bennett PH, Senter RG, Miller M. High prevalence of diabetes in young Pima Indians: evidence of phenotypic variation in a genetically isolated population. Diabetes 1979; 28: 937-42.

12. Ouchi N, Kihara S, Arita Y, Maeda K, Kuriyama H, Окамото Y eт al. Novel Modulator for Endothelial Adhesion Molecules: Adipocyte-Derived Plasma Protein Adiponectin. Circulation 1999; 100: 2473-6.
13. FrüHbeck G, Gómez-Ambrosi J, Muruzábal FJ, Burrell MA. The adipocyte: a model for integration of endocrine and metabolic signaling in energy metabolism regulation. Am J Physiol Endocrinol Metab 2001; 280: 827-47.

14. Goldstein BJ, Scalia R. Adiponectin: A Novel Adipokine Linking Adipocytes and Vascular Function. J Clin Endocrinol Metab 2004; 89: 2563-8.

15. Saltiel AR. You are what you secrete. Nat Med 2001; 7: 887-8.

16. PATTI ME, KaHN CR. The insulin receptor-a critical link in glucose homeostasis and insulin action. J. Basic Clin. Physiol. Pharmacol 1998; 9: 89-109

17. Shepherd PR, NAve BT, Siddle K. Insulin stimulation of glycogen synthesis and glycogen synthase activity is blocked by wortmannin and rapamycin in 3T3-L1 adipocytes: evidence for the involvement of phosphoinositide 3-kinase and p70 ribosomal protein-S6 kinase. Biochem J 1995; 305 : $25-8$.

18. Myers MG Jr, Backer JM, Sun XJ, Shoelson S, Hu P, SCHLESSINGER J ET AL. IRS-1 activates phosphatidylinositol 3'-kinase by associating with src homology 2 domains of p85. PNAS 1992; 89: 10350-4.

19. Antonetti DA, Algenstaedt P, Kahn CR. Insulin receptor substrate 1 binds two novel splice variants of the regulatory subunit of phosphatidylinositol 3-kinase in muscle and brain. Mol Cell Biol 1996; 16: 2195-203.

20. Peterson RT, Schreiber SL. Kinase phosphorylation: keeping it all in the family. Curr Biol 1999; 9: R521-R524.

21. Alessi DR. Characterization of a 3-phosphoinositide-dependent protein kinase which phosphorylates and activates protein kinase B alpha. Curr Biol 1997; 7: 261-9.

22. Brady MJ, Bourbonais FJ, Saltiel AR. The activation of glycogen synthase by insulin switches from kinase inhibition to phosphatase activation during adipogenesis in 3T3-L1 cells. J Biol Chem 1998; 273: 14063-6.

23. Сho H, Mu J, Kim JK, Thorvaldsen JL, Chu Q, Crenshaw EB $3^{\mathrm{RD}}$ ET AL. insulin resistance and a diabetes mellitus-like syndrome in mice lacking the protein kinase Akt2 $\left(\mathrm{PKB}^{\Re}\right)$. Science 2001; 292: 1728-31.

24. Elchebly M, Payette P, Michaliszyn E, Cromlish W, Collins S, LOY AL, ET AL. Increased insulin sensitivity and obesity resistance in mice lacking the 
protein tyrosine phosphatase-1B gene. Science 1999; 283: 1544-8.

25. Bush EN. Treatment of Zucker diabetic fatty rats with antisense oligonucleotide to phosphotyrosine phosphatase-1B for 5 weeks halts development of diabetes. Diabetes 2001; 50 (Suppl. 2): A81.

26. Yuan M, Konstantopoulos N, Lee J, Hansen L, Li ZW, KaRIN M ET aL. Reversal of obesity- and dietinduced insulin resistance with salicylates or targeted disruption of Ikkß. Science 2001; 293: 1673-7.

27. Kim JK, Kim YJ, Fillmore JJ, Chen Y, Moore I, Lee J ET AL. Prevention of fat-induced insulin resistance by salicylate. J Clin Invest 2001; 108: 437-46.

28. Moller DE. Potential role of TNF $\alpha$ in the pathogenesis of insulin resistance and type II diabetes. Trends Endocrinol Metab 2000; 11: 212-7.

29. Avignon A, Sultan A. PKC-B inhibition: a new therapeutic approach for diabetic complications? Diabetes Metab. 2006; 32: 205-13.

30. Porte D JR. Banting lecture 1990. Beta-cells in type II diabetes mellitus. Diabetes 1991; 40: 16680.

31. Drucker DJ. Minireview: the glucagon-like peptides. Endocrinology 2001; 142: 521-7.

32. Miyawaki K, Yamada Y, Yano $\mathrm{H}$, Niwa H, Ban N, IHARA Y ET AL. Glucose intolerance caused by a defect in the entero-insular axis: a study in gastric inhibitory polypeptide receptor knockout mice. PNAS 1999; 96: 14843-7.

33. Marguet D, Baggio L, Kobayashi T, Bernard AM, Pierres M, Nielsen PF ET Al. Enhanced insulin secretion and improved glucose tolerance in mice lacking CD26. PNAS 2000; 97: 6874-9.

34. Hinke SA, Pospisilik JA, Demuth HU, Mannhart S, Kunn-Wache K, Hoffmann T et al. Dipeptidyl peptidase IV (DPIV/CD26) degradation of glucagon. Characterization of glucagon degradation products and DPIV-resistant analogs. J Biol Chem 2000; 275: 3827-34.

35. Defronzo RA, Ratner RE, Han J. Effects of exenatide(exendin-4) on glycemic control and weight over 30 weeks in metformin-treatedpatients with type 2 diabetes. Diabetes Care 2005; 28: 1092-100.

36. Kendall DM, Riddle MC, Rosenstock J. Effects of exenatide(exendin-4) on glycemic control over 30 weeks in patients with type 2 diabetestreated with metformin and a sulfonylurea. Diabetes Care 2005; 28: 1083-91.

37. Drucker DJ, Nauck MA. The incretin system: glucagon-like peptide-1 receptor agonists and dipeptidyl peptidase- 4 inhibitors in type 2 diabetes. Lancet 2006; 368: 1696-705.

38. Asensio C, Muzzin P, Rohner-Jeanrenaud F. Role of glucocorticoids in the physiopathology of excessive fat deposition and insulin resistance. Int $\mathrm{J}$ Obes Relat Metab Disord 2004; 28(S4): S45-S52.

39. SARABU R. Metabolic diseases drug discovery world summit. July 28-29, 2003, San Diego, CA, USA. Expert Opin Investig Drugs 2003; 12: 1721-6.

40. Wright SW, Hageman DL, Mcclure LD, Carlo AA, Treadway JL, Mathiowetz AM et al. Allosteric inhibition of fructose-1,6-bisphosphatase by anilinoquinazolines. Bioorg Med Chem Lett 2001; 11: 17-21. 